\title{
Resumos
}

\section{RECURSOS FLORESTAIS NO BRASIL}

Depois de estar, por longo período, sendo gerado fora do país, o conhecimento a respeito da natureza brasileira foi aos poucos se transformando em negócio exclusivo do Estado brasileiro.

Em 1907, o Ministério da Agricultura constituiu-se, através do Serviço Geológico e Mineralógico do Brasil, do Museu Nacional e do Observatório Nacional, em órgão de ponta na absorção, geração e difusão do conhecimento técnico e científico, mobilizando os melhores talentos disponíveis, estrangeiros ou nacionais, podendo assim, a partir de 1909, processar o reconhecimento do território nacional.

Depois de inúmeras alterações, o governo introduz, em meados dos anos 60, a concessão de incentivos fiscais na área de reflorestamento, criando-se ao mesmo tempo, a necessidade de um órgão específico para administrar a nova política.

Criou-se, então, o Instituto Brasileiro de Desenvolvimento Florestal - IBDF, através da fusão do Instituto Nacional do Pinho e o Departamento de Recursos Naturais Renováveis, enunciando-se, entre as suas competências prioritárias, uma consciência bastante ampla acerca da inter-relação entre utilização e preservação dos recursos florestais.

\section{SISTEMA DE PARQUES NACIONAIS E RESERVAS BIOLÓGICAS DO BRASIL}

Em 1943, o Brasil tornou-se signatário da Convenção para a Proteção da Flora, da Fauna e das Belezas Cênicas Naturais dos Países da América. A partir de então, foram, gradativamente, criados vários parques nacionais e reservas biológicas, visando proteger e preservar unidades importantes ou sistemas completos de valores naturais ou culturais, proteger recursos genéticos, desenvolver a educação ambiental, oferecer oportunidades para a recreação pública, proporcionar facilidades para a investigação e outras afins de caráter científico, proteger amostras ecológicas representativas do meio ambiente natural para estudos científicos, monitoramento ambiental e educação científica.

O Brasil possui, hoje, 25 parques nacionais e doze reservas biológicas, que representam aproximadamente 11.000 .000 de hectares, ou seja, $1,5 \%$ do território nacional.

\section{UNIDADES DE CONSERVAC̣ÃO}

As unidades de conservação são áreas estabelecidas em ecossistemas significativos do território nacional, protegidas pelos governos federal, estaduais e municipais, que têm a finalidade de, entre outras, preservar bancos genéticos de fauna e flora, proteger os recursos hídricos e paisagens de relevante beleza cênica e conduzir de maneira apropriada a educação ambiental.

Entre as unidades de conservação, destacamos duas categorias que vêm preencher as lacunas existentes no sistema: as estações ecológicas e as áreas de proteção ambiental.

As estações ecológicas protegem áreas que apresentam fauna e flora de interesse significativo, bem como permitem que, em até $10 \%$ do total da área, dependendo do que for determinado no zoneamento, sejam realizadas pesquisas que alterem 0 ecossistema. Esse é o ponto fundamental de distinção das outras categorias dando condições e incentivos a que universidades brasileiras desenvolvam trabalhos integrados tanto no ecossistema protegido quanto no entorno, possibilitando equilibrar desenvolvimento com conservação.

As áreas de proteção ambiental - APA's, objetivam, através de um zoneamento, direcionar o uso do solo, compatibilizando, 
dentro da APA, a atividade humana com o conservacionismo, tendo como pré-requisito a criação de uma zona de vida silvestre.

\section{ECOLOGIA MARINHA}

Há, hoje, muitos pesquisadores estudando os mais diversos aspectos da ecologia marinha. No Brasil, os principais institutos estão em Recife, Rio de Janeiro, São Paulo, Paraná e no Rio Grande do Sul. Uma das principais características do trabalho oceanográfico é a sua multidisciplinaridade. Além disso, não existem limites políticos ao estudo do oceano, pois seus processos nada tem a ver com os mesmos.

Entre os principais aspectos desse trabalho estão o fluxo de energia através das comunidades biológicas marinhas, até $o$ homem que se utiliza de muitos produtos do mar, como ostras, mariscos, camarões, peixes, etc. Infelizmente são muito poucas as áreas efetivamente produtivas dos oceanos e dentre elas destacam-se os estuários, os ambientes costeiros, atualmente mais degradados pelo homem. Com isso, estamos destruindo áreas de inestimável valor ecológico e que muito poderiam continuar a oferecer às nossas populações tão necessitadas de alimentos. Com a poluição marinha estamos perdendo o que poderia efetivamente se constituir em áreas de aquacultura, de lazer na região costeira, e o que é mais grave, comprometendo por vezes seriamente, a nossa própria saúde.

\section{A SITUAÇÃO FLORESTAL DO RIO GRANDE DO SUL}

Conhecido como um estado agropastoril por excelência, com uma fisionomia de grandes áreas de cultivos e campos de criação, o Estado do Rio Grande do Sul possui uma acentuada tendência florestal, e que, originalmente, era predominantemente coberto por florestas, com uma área minoritária de campos.

Atualmente, qualquer área de terras abandonadas no sul sempre tende a uma vegetação de maior porte, tendo como resultado um clímax florestal, excetuando-se áreas do pampa e outras pequenas áreas em que problemas edáficos não o permitem. Pode-se comprovar, também, através do método dos diagramas de Walter, em dados climáticos do Estado, que o resultado é sempre um saldo positivo de água no ambiente, o que é um bom indício de clima propício a florestas.

Quanto às estimativas de cobertura florestal atual, estas são divergentes. Dados recentes, obtidos por satélites, ainda não publicados, avaliam esta cobertura em aproximadamente $6 \%$ da superfície do Estado.

Sabe-se que os remanescentes das matas originais são cada vez mais raros e encontram-se em péssimo estado, excetuando-se as pequenas e poucas reservas florestais, existentes no Estado que, por sua vez, estão ameaçadas por outros fatores, tais como, barragens, disputas judiciais e invasões.

O Estado do Rio Grande do Sul sofre, hoje, as conseqüências da devastação florestal e é preciso tomar providências no sentido de se recuperar esta perda. Sabe-se que a maneira mais simples, mais barata e mais lógica de se restaurar, regenerar ou reflorestar com espécies nativas é, simplesmente, abandonar e não interferir nas áreas para isto previstas, a fim de que a natureza se encarregue do processo.

\section{DESERTIFICAC̣ÃO}

Desertificação é a degradação progressiva dos ecossistemas naturais de uma área, resultante de fatores naturais ou da ação do homem e, geralmente, de ambos conjugadamente; é a redução do potencial biológico das terras, extensamente presente nas regiões tropicais que podem ou não colimar em deserto.

As mudanças de climas, expressas principalmente numa crescente deficiência de chuvas $e$ a ação do homem, são fatores que podem levar à desertificação de uma determinada área.

No Brasil, a desertificação vem se apresentando como uma ameaça em várias de suas áreas, principalmente no nordeste, 
no polígono das secas, que é a região brasileira mais comprometida com o processo de desertificação.

A vegetação que recobre o solo de uma área é um indicador evidente e seguro de sua vocação ecológica, que nas regiões semiáridas tende espontaneamente para a desertificação. Porém, é o fenômeno do "retirante", muito comum no nordeste, que constitui o indicador mais expressivo do processo de desertificação, considerando-se que o fenômeno da fuga do homem de seu lugar de origem se dá principalmente porque o solo não está retribuindo ao seu esforço.

Entretanto, o grave problema da desertificação no Brasil não é de todos conhecido e raramente desperta preocupações de estudiosos ligados ao semiárido nordestino, que é a região mais seriamente atingida, e há ainda os que insistem em até mesmo ignorá-lo.

\section{O DOMINIO DOS CERRADOS: INTRODUC̣ÃO AO CONHECIMENTO}

$O$ polígono dos cerrados centrais brasileiros, muito embora tenha uma posição zonal em relação ao grande conjunto das savanas e cerrados da África Austral e da América Tropical, a nível dos espaços fisiogeográficos e ecológicos brasileiros, é apenas mais um dos grandes polígonos irregulares que formam o mosaico paisagístico do país. No Brasil, cerrados e cerradões se repetem por toda a parte no interior e margens da área nuclear dos domínios morfoclimáticos regionais.

O domínio dos cerrados, em sua região nuclear, ocupa predominantemente maciços planaltos de estrutura complexa, dotados de superficies aplainadas de cimeira, e um conjunto significativo de planaltos sedimentares compartimentados, situados em niveis que variam entre 300 e 1.700 metros de altitude; possui drenagens perenes para os cursos d'água principais e secundários, envolvendo, porém, 0 desaparecimento temporário dos caminhos d'água de menor ordem de grandeza, por ocasião do período seco do meio do ano; comporta de cinco a seis meses secos, opondo-se a seis ou sete meses relativamente chuvosos, é onde ocorre a maior massissividade, extensividade e homogeneidade relativa de formas topográficas planálticas do Brasil intertropical.

\section{OS CERRADOS, UM GRUPO DE FORMAS DE VEGETACCÃO SEMELHANTES ȦS SAVANAS}

Os cerrados, tipos de savanóides de vegetação, ocorrem no Brasil em larga escala $e$, hoje, acredita-se que o cerrado será o grande celeiro, não só para produção de alimentos, mas de celulose, madeira para móveis, para consumo interno e para exportação, como também poderá servir para a formação de pastagens, que com um bom manejo permitirão um ótimo desenvolvimento da pecuária leiteira e de corte.

Os diferentes tipos de cerrados distribuem-se, no Brasil, em duas áreas principais: a chamada área nuclear, essencialmente de cerrados, no Planalto Central, e a área periférica, que distribui-se pelo norte, nordeste e sul. A superfície do Brasil ocupada por essa vegetação é de $22 \%$ aproximadamente.

\section{AVES DO CERRADO}

A região dos cerrados tem uma avifauna bastante rica, adaptada aos diversos tipos de vegetação do centro-oeste. Apenas $11 \%$ das aves do cerrado e caatinga são endêmicas. Encontram-se no cerrado aves da Região Amazônica, e outras pertencentes a grupos da Mata Atlântica, bem como representantes de várias famílias provenientes do Velho Mundo.

A maioria das aves do cerrado restringem-se a apenas um ou dois de seus habitats, como a mata ciliar, o cerrado stricto sensu, ou o campo limpo. Os tipos de vegetação de estrutura mais complexa contêm o maior número de espécies, sendo que a avifauna mais pobre é a sentença ao campo limpo.

Os movimentos migratórios e a reprodução estão as cociados ao forte ritmo sazonal de chuvas, e aparentemente à variação na 
disponibilidade dos insetos de que se alimentam a maioria das aves do cerrado.

A ação do homem ao ocupar a região dos cerrados está alternando a proporção primitiva dos vários habitats, e criando novos biótopos. Como resultado, também a composição da avifauna tem sido alterada. De especial interesse é o estudo de interações entre espécies que anteriormente não apresentam contatos mútuos extensivos.

\section{SISTEMA ORGÂNICO PARA A GESTÃO AMBIENTAL - PROPOSTA DE UM SISTEMA ADEQUADO}

A centralização das decisões é uma técnica organizadora destinada a favorecer os que facilmente podem chegar ou dirigir-se ao centro. A verticalização das decisões tem prejudicado contínua e consideravelmente $o$ meio ambiente. A ausência de comprovação da capacitação inicial e subseqüëncia do pessoal dos organismos administrativos ambientais tem sido uma das causas do insucesso da política ambiental. O Estado ou - Poder Público no caso dos bens ambientais é mero gestor desses bens, tendo em vista seu uso coletivo. Não só com referência aos direitos individuais, mas também aos direitos sociais e, notadamente, na gestão dos bens ambientais, a ausência de fundamentação dos atos da administração tem levado ao aumento da poluição e da devastação da natureza.

No direito ambiental e em sua organização administrativa deve-se estabelecer, sem ambiguidades, uma dupla mão de direção na informação: direito de informação e dever de informação. Do conhecimento dos fatos, os cidadãos e os grupos sociais passaram a querer participar do procedimento de elaboração das decisões, já na fase do planejamento ambiental. Esta participação não merece ser realizada e nem é totalmente eficaz se for feita somente por via parlamentar. O meio ambiente deve ter da parte dos países primeiramente uma política global, ampla e geral.

Não se pretende uma política uniforme, mas que examine as desigualdades ecológicas, econômicas, demográficas e culturais e lhes dê o tratamento devido. Não se deve impedir que as entidades menores tenham competência no controle ambiental. A concepção de um sistema nacional de meio ambiente poderá possibilitar uma participação integrada. Preconiza-se uma administração que tenha característica própria e autônoma, com um estatuto adequado para seus componentes, assegurando-se a estes independência $e$ idoneidade nas decisões e produtividade eficaz na gestão dos recursos ambientais. O Ministério Público Federal e Estadual no Brasil poderão exercer uma intervenção administrativa mediadora e preventiva. Enfim, não se podem criar oportunidades para uma administração ambiental monolítica e fechada em si mesma, com unidade de canais de comunicaçốes e de decisões, dando-se chance para erros de inoperância, de ações malconcebidas ou mal-executadas.

\section{TEORIA ECONÔMICA E MEIO AMBIENTE}

Para a teoria econômica, a natureza é apenas um depósito de recursos naturais que devem ser transformados em bens e serviços da forma mais rápida possível. A teoria econômica ignora, desta forma, o impacto ecológico das atividades produtivas. Isto se deve, sobretudo, ao êxito do avanço técnico ocorrido nos últimos duzentos anos, o que permitiu o crescimento contínuo (salvo últimos curtos períodos de depressão) da produção econômica. $O$ avanço técnico permitiu a ridicularização dos prognósticos malthusianos de que a Terra apresentava um limite ao crescimento econômico, prevalecendo na conseqüência uma visão otimista, entre todos os economistas, fossem de formação neoclássica ou marxista.

Modernamente, devido à realidade do consumismo e graças aos instrumentais de análise de sistema, de processamento de dados e ao acúmulo de dados estatísticos, 0 otimismo deu lugar a uma grande dúvida sobre o futuro da economia mundial, ao constatar-se que, de um lado, há o risco de esgotamento real de recursos naturais antes que a tecnologia os substitua por outros mais baratos e, de outro, a sociedade começa a 
pagar um elevado custo decorrente da poluição ambiental.

Lamentavelmente, a ciência econômica "tradicional" encontra-se impotente para incorporar o problema do meio ambiente nas suas análises, devido aos seguintes aspectos: a visão nacional em que baseia sua análise; as dificuldades de prever-se modificações tecnológicas e sociais dentro do curto horizonte em que a ciência considera seu processo; e, finalmente, a característica de tratar com os meios materiais de satisfação e não com a própria razão de ser do homem. Isto porém, pode ser em parte superado se se incorporam modificações na visão economicista, tanto ao nível macro como ao nivel micro.

\section{TRANSFERÊNCIA DE TECNOLOGIA E MEIO AMBIENTE}

A transferência de tecnologia é um fenômeno que sempre ocorreu ao longo da história. Todas as sociedades criavam tecnologias adequadas ao seu meio ambiente físico $e$ humano, podendo ou não produzir efeitos nocivos sobre o meio ambiente. E o fato de os países subdesenvolvidos utilizarem tecnologias importadas indiscriminadamente tem uma importância fundamental em função do seu efeito sobre o meio ambiente.

Esses efeitos, entretanto, podem ser atenuados até a níveis toleráveis e, para tanto, é preciso que a população afetada tenha consciência do dano e da sua origem, possuindo capacidade de atuação para exigir soluções e, ainda, que possua os conhecimentos e os recursos humanos materiais necessários para idealizar e aplicar soluções.

\section{A POLITICA NACIONAL PARA OS RECURSOS DO MAR}

A Política Nacional para os Recursos do Mar, aprovada em 1980, fixa os objetivos básicos do setor de recursos do mar que são executados exclusivamente pelo governo federal, através da Comissão Interministerial para os Recursos do Mar - CIRM, objetivos estes que enfocam aspectos jurídicos, educacionais, científicos e tecnológicos, etc. O I Plano Setorial para os Recursos do Mar - I PSRM, consubstanciado em cinco programas, busca viabilizar a consecução dos objetivos da Política Nacional para os Recursos do Mar, através da definição dos interesses básicos do Brasil no mar, quais sejam: alimentos, matérias-primas e energia.

\section{CONSIDERACÕES SOBRE A EDUCAÇÃO ÁMBIENTAL E O PAPEL DO ESTADO}

De acordo com a lei que instituiu, no Brasil, a Política Nacional do Meio Ambiente, não existe, no país, uma consciência ecológica conseqüente, ou seja, ela não atinge a população em grandes proporções. A falta de ideologia ambiental, no país, se justifica pelo fato de que, ainda que se desenvolva em ritmo acelerado, o processo de industrialização e de urbanização mal superou os seus primeiros estágios. A questão da preservação e da melhoria ambiental tornou-se uma questão política, exigindo dos indivíduos e de grupos sociais resultados através de suas atitudes, decisões, hábitos e comportamentos. Criar novos padrões valorativos que regulem as relações entre os indivíduos, a sociedade e o meio ambiente corresponde ao que chamamos de formação de uma consciência (ou ideologia) ambiental.

É legítimo que o Estado atue no sentido de acelerar o processo de formação de uma consciência ambiental, intervindo nesse processo através de vários níveis: educação formal, mediante inclusão obrigatória dos temas ambientais nos currículos escolares, em todos os níveis de ensino; formação de quadros técnicos para a gestão dos recursos ambientais; educação de massa visando a reorientação de hábitos de indivíduos concretos (ou comunidades restritas) em suas ações concretas e passíveis do seu controle.

\section{ECOLOGIA URBANA: 0 PLANEJAMENTO URBANO E O AMBIENTE ALTERADO DAS CIDADES}

O planejamento urbano, no Brasil, 
influenciado pela estratégia geral de consumo e pela crise sócio-econômica, não leva em consideracão o ambiente natural onde as cidades são construídas. Resultam dessa indiferença, alterações no ambiente e o surgimento de ecossistemas artificiais, que diminuem a qualidade de vida. Estas alterações são provavelmente uma das causas de enchentes e aumento das populações urbanas, e conseqüentemente graves problemas na área de saúde.

As poucas informações que se tem sobre os ecossistemas naturais de regiões agrava, ainda mais, os problemas nos centros urbanos. Geralmente, o que ocorre é uma adaptação dos estudos sobre os ecossistemas de clima frio e temperado para a região tropical.

É necessário, portanto, o estudo dos ecossistemas onde as cidades se inserem, como contribuição ao planejamento urbano.

\section{CONSERVACÃO E UTILIZACCÃO RACIONAL DOS RECURSOS HIDRICOS}

$O$ crescimento vertiginoso e a expansão das atividades agricolas e industriais, nas últimas décadas, ocasionaram uma elevação acelerada da poluição hídrica, provocada por esgotos urbanos, metais pesados, pesticidas, adubos químicos, etc., ocasionando, conseqüentemente, vários problemas para a população.

O conjunto de ações a serem desenvolvidas, visando garantir às populações e às atividades econômicas uma utilização otimizada da água, em termos de qualidade como de quantidade, é o que se poderia chamar de "gerenciamento de recursos hídricos", podendo ser, conforme os casos, de caráter político, legislativo, econômico, de coordenação, de pesquisa, de formação de pessoal, de informação e de cooperação intersetorial, ou mesmo internacional.

No Brasil, uma das primeiras tentativas de equacionar globalmente o problema de desenvolvimento de uma bacia hidrográfica, foi levada a efeito pela antiga Comissão do Vale do São Francisco - CVSF. Outro exemplo é o da Comissão Mista BrasilUruguai, visando o desenvolvimento sócioeconômico da região compreendida pela Bacia da Lagoa Mirim.

Inspirado em experiências desenvolvidas nas bacias do Alto Tietê e Cubatão e em experiências internacionais, o governo federal, criou o Comitê Especial de Estudos Integrados de Bacias Hidrográficas CEEIBH, que tem por finalidade realizar o estudo integrado e acompanhar a utilização dos recursos hídricos de bacias hidrográficas dos rios federais, tendo em vista garantir o seu aproveitamento múltiplo e a minimização de conseqüências nocivas ao meio ambiente.

\section{PROBLEMAS DE POLUIC̣ÃO NO PARANÁ}

O problema da poluição atinge seriamente todos os estados brasileiros e o Paraná, especificamente, enfrenta uma série de problemas decorrente de um desenvolvimento industrial e populacional malprogramado que, conseqüentemente, provoca poluição

A poluição no Estado do Paraná decorre de vários fatores, tais como, o elevado grau de industrialização, a migração contínua do homem do campo, o uso abusivo e indiscriminado de defensivos agrícolas e $o$ desmatamento acentuado em função de áreas de plantio, entre outros.

Diante disso, a Superintendência de Recursos Hídricos e Meio Ambiente Surehma, entidade responsável pela coordenação das ações do Estado relativas ao meio ambiente, tenta, através de seus meios legais, sanar os problemas advindos destes fatores.

Entre as medidas preventivas tomadas pela Surehma, além da legislação federal e estadual vigentes, para melhorar a situação do Estado no referente à poluição, estão os convênios firmados com o Banco de Desenvolvimento do Estado do Paraná Badep, Companhia Paranaense de Energia Elétrica - Copel, prefeituras municipais e a criação de várias associações conservacionistas, visando a fiscalização corretiva e preventiva junto às indústrias. 


\section{POLUICCÃO DO AR NAS ÁREAS METROPOLITANAS DE SÃO PAULO - SITUAC̣ÃO ATÉ MARC̣O DE 1983}

A poluição do ar na Região Metropolitana de São Paulo - RMSP, constitui-se num sério problema de saúde pública. As concentrações, na atmosfera dessa região, dos poluentes dióxidos de enxofre, material particulado, monóxido de carbono e oxidantes fotoquímicos, estão acima dos respectivos padrões de qualidade do ar, tornando-a uma região saturada em termos de poluição do ar, de acordo com os padrões estabelecidos pela legislação estadual.

As ações de controle que vem sendo desenvolvidas pelo governo do Estado, já há quase dez anos, lograram diminuir o risco de episódios agudos de poluição do ar durante $o$ período de inverno, bem como evitar o agravamento do problema por material particulado. Além do controle das emissões existentes, que deve ser acelerado, uma série de medidas indiretas devem ser desencadeadas pelo governo, visando a adoção de alternativas energéticas nãopoluidoras, como a energia elétrica e o gás combustivel, tanto nas fontes estacionárias, como nas fontes móveis; a adoção de um sistema de licenciamento estadual que possibilite o crescimento do parque industrial da RMSP, dentro de uma tipologia industrial não-poluidora; o incentivo à pesquisa e ao desenvolvimento de tecnologia, buscando alternativas de soluções não-alienígenas, $e$ que tenham o devido respaldo popular.

\section{CONTROLE AMBIENTAL EM FÁBRICAS DE PAPEL E CELULOSE}

$O$ conhecimento do assunto poluição pressupõe uma análise do processo de interação das atividades com o meio que a circunda. Essa análise não deve se restringir aos aspectos tangíveis da questão, mas se extrapolada aos aspectos sociológicos.

O fenômeno poluição é um sinergismo entre vários fatores, dos quais, pode-se destacar a concentração industrial e urbana $e$ as insatisfações da população.

$O$ aspecto preventivo do controle ambiental é muito mais eficaz que o corretivo, o que não tem sido devidamente cuidado pelas autoridades governamentais, e por isso mesmo, hoje, são necessários recursos vultosos para solucionar problemas já identificados.

A indústria de celulose e papel, por imprevisão, erro ou omissões no passado, se destaca, no conceito da população, dentre aquelas atividades mais adversas ao meio ambiente.

Erroneamente, inclusive, estende-se o efeito ambiental de fabricação de celulose à fabricação de papel, quando esta atividade praticamente não causa efeitos ao meio ambiente. A própria fabricacãa de celulose, desde que adotadas as práticas conhecidas, tem um impacto ambiental bem reduzido.

Trabalhos conjuntos importantes vêm sendo realizados pela entidade que congrega os fabricantes de celulose e papel e aqueles de controle ambiental, não só no que se refere à poluição, propriamente dita, como também no sentido de desmistificar o conceito predatório de floresta homogênea.

\section{OCUPAC̄ÃO DA AMAZŌNIA E DEFESA FLORESTAL}

A selva equatorial da América representa a maior reserva de biomassa e oferece grande variedade de produtos. Cobre quase todo o norte do Brasil e sua origem está relacionada à transgressão flandriana. Como formaçãoclímax, ela é auto-sustentada e reveste grande variedade de solos. A água da chuva é reciclada várias vezes piela Floresta Amazônica. Sua devastação acarretará um desequilíbrio ecológico irreparável.

Os projetos de aproveitamento das terras florestais da Amazônia são esquematicamente divididos em três fases: colonização por pequenos proprietários, ao longo de novas rodovias; grandes projetos agropecuários; e projetos madeireiros. Os resultados têm sido desapontadores $e$ ameaçam extinguir a floresta em breve prazo. A hiléia amazônica deve ser conservada quase inteiramente intacta. Áreas dispersas e cuidadosamente escolhidas devem ser cultivadas, com aplicação de sistemas 
agrícolas e agrossilviculturais bem-sucedidos nos trópicos úmidos da Ásia e África.

Experimentos com espécies nativas devem ser intensificados.

\section{AVES DA MATA ATLĀNTICA EM EXTINCุÃO}

A diminuição das aves do Brasil é muito grande devido à destruição de habitat, captura para comércio ilegal de aves vivas e a caça ilegal. Uma das áreas mais atingidas pela predação humana é a Mata Atlântica. As principais aves dessa região que se encontram ameaçadas, estão alistadas. Há necessidade de uma conservação mais eficiente das aves da Mata Atlântica pela criação de mais reservas e uma fiscalização mais rigorosa que garantam a sobrevivência dessa fauna única no Brasil.

\section{MIGRAC̣ÃO DE AVES NA REGIÃO DO CERRADO DO BRASIL CENTRAL}

A movimentação de animais sempre foi um fenômeno que atraiu a atenção do homem. A migração de aves - mecanismo que permite a sobrevivência de várias espécies, por milhares de anos - é um desses fenômenos que continua a encantar o homem.

Das 1.580 espécies de aves catalogadas para o Brasil, 119 são migratórias, que podem ser classificadas em três tipos: nas espécies da América do Norte, que passam pelo Brasil ou aqui invernam; nas espécies que reproduzemse no sul do Brasil e no Cone Sul, migrando ou invernando no centro e no norte do Brasil; e, finalmente, nas espécies que reproduzemse e invernam dentro do Brasil.

Na região do cerrado do Brasil Central vamos encontrar várias espécies migratórias, devido à diversidade vegetacional existente nesta região. Entretanto, é no final da seca e início das chuvas que a região do Brasil Central assiste a mais espetacular migração de aves.

Porém todo esse movimento, que permite a sobrevivência de várias espécies, encontra-se, hoje, ameaçado por vários fatores, quais sejam, a poluição, alterações do ambiente $e$ até mesmo massacres dessas aves. Tudo isso requer, mais do que nunca, conscientização de todos, para que estas aves continuem o seu ciclo infindável de movimentação.

\section{ESPÉCIES AMEAC̣ADAS DE EXTINÇÃO NA AMAZÔNIA}

Existem várias espécies ameaçadas de extinção no Brasil e, em particular, na Amazônia. Entretanto, é difícil classificá-las nesta região, devido à imensidão da área e a falta de conhecimento de todo o seu potencial florístico e faunístico.

Estas espécies que se encontram hoje ameaçadas têm um reconhecido valor, seja pela alta quantidade de proteínas que possuem e até mesmo por servirem a indústrias de vários tipos. Hoje estão praticamente dizimadas devido à sua exploração desenfreada, sem que haja, uma fiscalização que pudesse impedir a sua redução em grande escala.

Diante desse quadro, o governo brasileiro foi impulsionado a promover leis de proteção da fauna e da flora, e através do Instituto Brasileiro de Desenvolvimento Florestal IBDF, e da Secretaria Especial do Meio Ambiente - SEMA, tenta preservar e proteger os nossos recursos naturais.

O objetivo da conservação da natureza é a poupança dos recursos naturais para garantir a sua disponibilidade no futuro, podendo ser a exploração desses recursos admitida, uma vez que tal exploração seja efetuada utilizando-se conceitos de manejo responsável.

\section{O HOMEM FRENTE ÀS PRAGAS}

A estimativa referente aos danos causados por insetos na produção agrícola mundial atinge, a cada ano, de 10 a $15 \%$, e as medidas usadas para combatê-los pode vir a acarretar conseqüências drásticas sobre o meio ambiente.

Realizado há praticamente um século, 0 combate químico das pragas, resultou, em muitos casos, em notáveis benefícios ao homem em termos de incremento na 
produção de alimentos; mostraram ser ineficazes, no caso de algumas pragas e constatou-se, também, o surgimento de muitos problemas novos em decorrência de seu uso.

Nos agroecossistemas, ambientes criados pelo homem com a agricultura, ocorre a presença em altas densidades de vários insetos e porque causam prejuízos econômicos ao próprio homem, são classificados como "pragas", o que não ocorre, entretanto, em seus ambientes naturais, onde as tendências para uma aumento nos números parecem estar contrabalanceadas por uma série de pressões opostas a este mesmo crescimento.

\section{A PESCA DA BALEIA, UMA ADVERTÉNCIA PARA O FUTURO}

A pesca aos grandes cetáceos, vulgarmente denominados baleias, data de tempos imemoriais, entretanto, nos dois últimos séculos ela atingiu proporções drásticas, que chega a colocar em risco de extinção todos os estoques ainda existentes.

Foi, entrementes, no Século $X X$ que se presenciou o grande massacre, atingindo-se, na década de 60, a absurda cifra de 66.000 baleias capturadas em um só ano.

\section{Instituiu-se, em 1946, a Comissão} Internacional para a Pesca da Baleia - ClB, na tentativa de racionalizar a matança irresponsável por parte daqueles que só visam o lucro e colocam em risco a vida de várias espécies.

No Brasil, a captura comercial de baleias contribuiu de forma expressiva para o extermínio das populações locais de várias espécies. Houve, por parte de conservacionistas, apelos no sentido de se convencer as autoridades brasileiras a proibir as capturas no nordeste. Entretanto, os interesses comerciais se mostraram mais poderosos. Assim, só temos que lastimar a política anticonservacionista que o nosso país adota, com proveito exclusivo de uma atividade comercial, reconhecidamente predatória e condenada pela opinião pública mundial.

\section{DEFENSIVOS AGRICOLAS - EFEITOS NO HOMEM E NO AMBIENTE}

Defensivos agrícolas ou praguicidas são objeto de discussões e controvérsias, atingindo praticamente os interesses de toda a comunidade.

De acordo com o Grupo de Trabalho sobre Princípios de Regulamentação, do Comitê do Codex Alimentarius sobre Resíduos de Pesticidas, praguicida significa qualquer substância destinada a prevenir, atrair, repelir ou controlar qualquer praga, durante a produção, armazenamento, transporte, distribuição e processamento de alimentos, produtos agrícolas ou rações animais. Podese também referir a substâncias usadas como reguladoras de crescimento de plantas, desfolhantes, dessecantes, antibrotantes e àquelas que são aplicadas às culturas antes ou logo após a colheita, para proteger os produtos, durante $\mathrm{o}$ armazenamento ou transporte.

A descoberta do DDT e a utilização dos organofosforados, logo após a II Guerra Mundial, veio marcar a nova era química. Pesquisas foram desenvolvidas visando a produção de praguicidas. Deve ser avaliado, contudo, o risco que a utilização desses agentes químicos provoca nos sistemas naturais que passou a exigir, em escala cada vez maior, uma constante preocupação por parte de quem os utiliza, devendo ser considerados os efeitos nocivos que deles advêm direta ou indiretamente.

Os efeitos nocivos dos defensivos agrícolas podem se acentuar conforme uma utilização inadequada e desnecessária. Não existe o praguicida ideal: todos, de uma maneira ou outra, podem desencadear problemas; isto faz com que se procurem, cada vez mais, pela pesquisa, novas formas de controle $e$ erradicação de pragas e utilização de produtos com segurança, sem contaminação do ambiente, visando a segurança das populações.

\section{RESÍDUOS DE DEFENSIVOS AGRÍCOLAS NOS ALIMENTOS}

A preocupação constante que têm tanto 